\title{
DECISÕES DE PREÇO EM CLIMA DE INCERTEZA: UMA CONTRIBUIÇÃO DA ANÁLISE BAYESIANA
}

Jorge Motta

Professor do Departamento de Mercadologia da EAESP/FGV e Coordenador do Curso de Administração de Marketing do Programa de Educação Continuada da EAESP/FGV.

RESUMO: Os administradores brasileiros revelam muitas vezes ter dúvidas sobre fatores importantes que determinam o sucesso de uma estratégia de estipulação de preço. Quando o nível de incerteza é grande e suas origens são numerosas, problemas de precificação aparentemente singelos podem rapidamente tornar-se inadministráveis. O objetivo deste artigo é descrever e analisar um método, denominado análise bayesiana, para lidar com essa complexidade. Com o uso deste procedimento, facilita-se a compreensão de problemas complexos e possibilita-se aos administradores melhorar suas decisões de fixação de preços.

ABSTRACT: Brazilian managers are often uncertain about important factors that determine the success of a pricing strategy. When the degree of uncertainty is large and its sources are numerous, apparently simple pricing problems can quickly become unmanageable. The purpose of this paper is to give an account of a procedure, Bayesian analysis, for dealing with that complexity. Using this procedure, complex problems become easier to understand, enabling managers to make better pricing decisions.

PALAVRAS-CHAVE: determinação de preço, decisões de preço em clima de incerteza, análise bayesiana aplicada a decisões de preço, teoria bayesiana de decisão.

KEY WOROS: price setting, pricing decisions under uncertainty, Bayesian decision theory in pricing strategy, Bayesian approach to pricing decisions. 
De todas as variáveis parcial ou totalmente controláveis do composto mercadológico, a determinação de estratégias de preço tem merecido a maior atenção dos economistas e autoridades responsáveis pelas políticas governamentais. Deve-se salientar, todavia, que a variável preço é apenas um entre diversos estimuladores internos e externos que afetam a procura de um produto ou serviço de uma empresa. Quando se afirma que o número de unidades de produto ou serviço a ser vendido é uma função do preço do bem $[Q=f(p)]$, omite-se o fato de que a procura é também uma função do preço dos produtos substitutos, gostos e renda dos consumidores, influências governamentais, e uma multiplicidade de outras variáveis internas controláveis, como qualidade do produto ou serviço, estrutura da via de distribuição, esforços e gastos promocionais, o programa da venda pessoal e assim por diante.

A estipulação de preço é uma das atividades mais importantes e complexas que o tomador de decisão do setor comercial deve enfrentar a fim de preparar e executar um programa mercadológico eficiente e lucrativo. Áreas de estudo e pesquisa tão diversas como economia, psicologia, sociologia, matemática, estatística, engenharia, pesquisa operacional e engenharia econômica têm contribuído com teorias, técnicas e programas que visam a converter a formação de preço num procedimento sistemático. A despeito das boas intenções e das valiosas contribuições de especialistas em cada um destes campos do conhecimento humano, as decisões de preços ainda são tomadas numa atmosfera de incerteza.

\section{FONTES DE INCERTEZA}

A incerteza que envolve as decisões do gerente de marketing refere-se a situações em que as conseqüências da decisão são conhecidas do administrador, porém não sucede o mesmo com as probabilidades de ocorrência desses resultados. A maioria das decisões tomadas na administração mercadológica são opções feitas em clima de incerteza. Quando, por exemplo, o tomador de decisão elege aumentar a verba de propaganda ou reduzir o preço de venda de seu produto ou serviço, ele conhece a amplitude de possíveis reações dos clientes e concorrentes, porém ignora as respectivas probabilidades. Pode expressar e usar probabilidades subjetivas ou crenças pessoais para fundamentar suas decisões, não podendo, todavia, recorrer a probabilidades objetivas, baseadas na freqüência relativa de ocorrência de um evento a ser esperada no longo prazo. Probabilidades objetivas, calculadas com base na freqüência relativa de ocorrência de um evento, são apropriadas à tomada de decisão em situação de risco, em que as consequiências possíveis de uma escolha e suas respectivas probabilidades são de conhecimento do agente decisório.

Se admitirmos a existência de incerteza na discussão de funções analíticas de procura $\mathrm{e}$ custo, tornar-se-á claro que a incerteza poderá surgir em diversos lugares. Consideremos a seguinte função de procura simples:

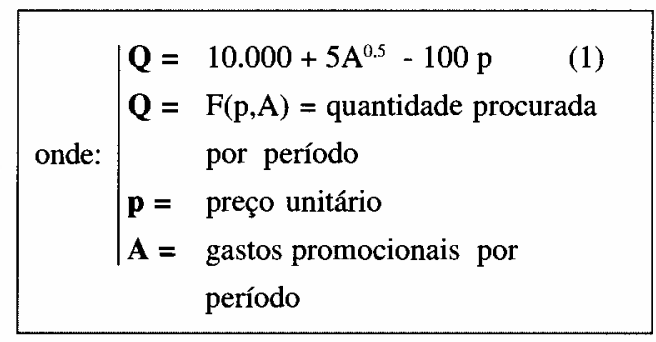

Kotler observa que se o tomador de decisão não confiar plenamente em que esta expressão poderá prever a procura com exatidão, será porque ele percebe que a incerteza está enraizada em uma ou mais destas cinco fontes, denominadas, respectivamente: (1) incerteza relativa à forma das variáveis; (2) incerteza referente aos coeficientes e expoente existentes na função; (3) incerteza relacionada com a estrutura da função; (4) incerteza decorrente da omissão de variáveis influenciadoras da procura; (5) incerteza associada à estabilidade da forma da função e pertinente aos coeficientes e expoentes vinculados à resposta da procura. Se a expressão (1) contivesse um termo $\mathrm{Y}$ correspondente à renda nacional, teríamos de lidar com uma sexta fonte, $a$ incerteza conseqüente à existência de uma variável exógena.'

Estas seis fontes de incerteza dizem respeito à função de procura em termos de variáveis do composto mercadológico (preço e investimentos promocionais) e, eventualmente, de uma variável externa. Por sua vez, a formação do preço de venda de um produto ou serviço requer a avaliação de componentes - custos, sensibilidade ao preço e concorrência que se revestem de um certo grau de incerteza. making New York: Holt, Rinehart and Winston. 1971, p. 252 
Analisaremos mais adiante o desenvolvimento de uma estratégia de preço compatível com essas variáveis ambientais incertas.

\section{MÉTOdOS DE FIXAÇÃO DE PREÇOS}

A determinação do preço de venda de um produto ou serviço é uma arte complicada, que envolve muitas considerações: elasticidade da procura, nível de operações da firma, estoques disponíveis, situação financeira da empresa, concorrência dentro de um mesmo ramo de

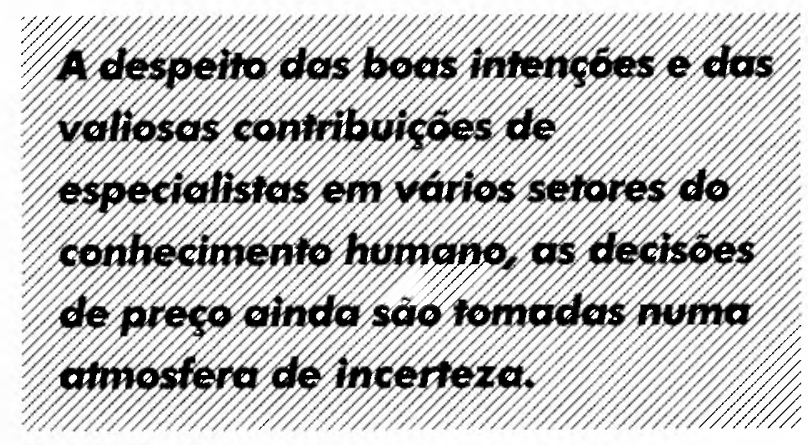

negócios e entre ramos diferentes, exclusividade de um produto ou serviço, restrições governamentais, importações de outros países e assim por diante. Por limitação de espaço, analisaremos apenas dois métodos de fixação de preço: as abordagens orientadas para custos $\mathrm{e}$ as voltadas para a concorrência.

\section{Formação do preço com base em custos}

Embora os executivos responsáveis pela determinação de preços usem inúmeros procedimentos do tipo regra-de-bolso, esta análise abrangerá apenas quatro dos mais refinados métodos baseados em custos : (1) custo pleno, (2) custo marginal, (3) retorno sobre o investimento e (4) custo flexível.

\section{Formação do preço com base no custo pleno}

De acordo com este método, os preços de venda resultam do acréscimo ao custo total de produção de uma quantia equivalente à soma das despesas de venda e administrativas e uma margem de lucro desejada. A principal vantagem do método do custo pleno é que ele assegura a recuperação total dos custos e a obtenção de uma margem de lucro planejada, o que é importante na formação de preços no longo prazo. Apesar de sua grande popularidade, existem, contudo, restrições definitivas ao custo pleno como base para determinação do preço:

1. O método ignora a elasticidade da procura. Como este procedimento não separa os custos fixos e variáveis, é impossível detectar que efeito uma variação de preço terá sobre os lucros.

2. O método do custo pleno não leva em consideração a concorrência. Consequientemente, nota-se a tendência de perpetuação das ineficiências existentes na empresa mediante a sua incorporação na estrutura de preços.

3. O método do custo pleno não faz distinção entre dispêndios que representam desembolsos reais e custos irreversíveis. Uma empresa que adota este método pode tender a recusar pedidos que não cubram, pelo menos, os custos totais envolvidos. A aceitação de tais pedidos sob certas condições, entretanto, poderia aumentar os lucros em vez de diminuí-los

4. Este método aplica uma porcentagem uniforme ao custo total de cada produto a título de provisão para o lucro. O método do custo pleno desconhece que nem todos os produtos podem auferir a mesma margem de lucro.

5. Neste sistema de formação do preço de venda, não se toma em consideração o investimento de capital exigido para produzir, financiar e comercializar produtos individuais ou linhas de produtos. A verdadeira medida da eficiência de uma empresa é obtida, entretanto, verificando-se se a companhia está tendo ou não um rendimento satisfatório sobre o capital investido.

\section{Método do custo marginal}

Custos marginais são custos acrescidos que se relacionam diretamente com o que é produzido e vendido. São custos que não ocorreriam se um produto fosse eliminado. Tais custos incluem: matérias-primas, mão-de-obra direta, custos indiretos variáveis de produção e despesas variáveis de vendas e administrativas. 
O método do custo marginal é particularmente útil no planejamento do lucro e nas decisões de preço no prazo curto.

Sob o ponto de vista da formação de preços, a diferença entre o custeio marginal e o custeio pleno está no conceito de recuperação dos custos. Com base no custeio pleno, espera-se que os preços cubram o total dos custos, inclusive os encargos fixos. $\mathrm{Na}$ abordagem do custeio marginal, qualquer contribuição à recuperação dos custos fixos é melhor do que nenhuma.

3. Método do retorno sobre o investimento

A formação do preço de venda pelos métodos do custeio pleno e custeio marginal não considera o investimento de capital exigido para fabricar, financiar e comercializar produtos ou linhas de produtos. $\mathrm{O}$ método do retorno sobre o investimento calcula o preço de venda de um produto com o objetivo de conseguir um índice

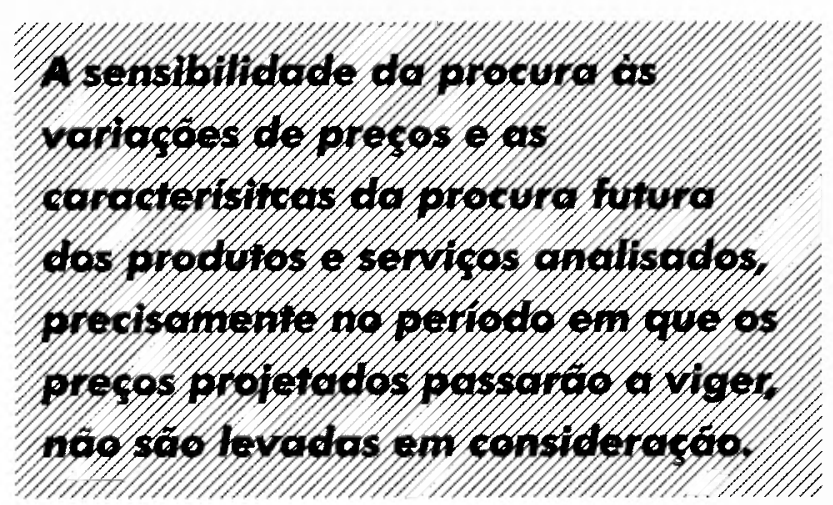

predeterminado de lucro sobre o capital empregado. A inclusão no preço de venda de um fator que leva em consideração o capital investido, assume importância particular nas empresas que produzem e comercializam uma multiplicidade de produtos, os quais requerem investimentos de capital diferentes para produtos ou linhas de produtos diversificados.

\section{Método do custo flexível}

Os três sistemas de determinação do preço de venda baseados em custos são os mais comumente utilizados em decisões de preço. Estes métodos não são mutuamente excludentes e cada um deles apresenta certas limitações. $O$ procedimento mais eficaz é aquele que pode combinar os atributos destacados dos três sistemas. Os executivos responsáveis pela formação do preço receberiam dados de custos flexí- veis que poderiam ser usados como diretrizes de preço.

À medida que ocorressem condições competitivas e internas diferentes, os administradores poderiam selecionar os custos e outros critérios quantitativos mais relevantes à situação de decisão.

\section{Formação do preço com base na concorrência}

Nos métodos de formação de preços orientados para a concorrência, a empresa opta por fixar seus preços de venda considerando principalmente os preços dos concorrentes e dedicando menor atenção aos seus próprios custos ou à procura de seus produtos. A empresa pode decidir cobrar preços iguais, maiores ou menores do que seus principais concorrentes. Nos setores oligopolísticos da economia que comercializam um bem homogêneo como aço, cimento, papel ou fertilizante, as empresas cobram normalmente o mesmo preço. As firmas menores "seguem o líder". Elas alteram seus preços quando os preços do líder mudam e não quando seus custos ou procura variam. Algumas companhias podem cobrar um prêmio pequeno ou oferecer um desconto pequeno, porém procuram manter a margem de diferença.

Os métodos de formação do preço de venda analisados neste artigo - quer se fundamentem em custos quer nos preços dos concorrentes - não devem ser empregados isoladamente em razão dessas deficiências:

1. As empresas que adotam esses sistemas - regras-de-bolso, mais apropriadamente - aparentam confiar em custos muito mais formalmente do que na procura por seus produtos ou serviços quando precisam tomar decisões de preço. Esta dependência se deve em grande parte à maior habilidade dos empresários de estimar este termo da equação do lucro.

2. Os custos escolhidos, contudo, são custos integrais e históricos em lugar dos custos incrementais e futuros dos economistas teóricos.

3. A sensibilidade da procura às variações de preço e as características da procura futura

$R A E$ ・ v. 37 • n. 2 - Abr./Jun. 1997 
dos produtos e serviços examinados, precisamente no período em que os preços projetados passarão a viger, não são levadas em consideração.

4. O papel desempenhado pelos concorrentes parece ser avaliado mais no aspecto defensivo do que ofensivo, levando um observador atento a concluir que a empresa está mais interessada em "deixar como está para ver como fica".

5. A ênfase parece ser mais dirigida a garantir um "lucro normal" do que a aceitar o maior risco assumido decorrente da política de fixar o preço de venda com o propósito de obter lucros máximos.

Como foi observado no subtítulo "Fontes de Incerteza", a formação do preço de venda de um produto ou serviço exige o exame de três componentes - custos, sensibilidade da procura às variações de preço e respostas retaliatórias dos concorrentes a essas alterações de preço. Thomas T. Nagle recomenda que as preocupações seguintes sejam tomadas para compatibilizar a formulação de uma estratégia de preço com esses três componentes incertos:

1. Identificar os custos incrementais e evitáveis que são aplicáveis a uma alteração das vendas.

2. Calcular a margem de contribuição e a variação das vendas em equilíbrio relativas à mudança de preço proposta.

3. Avaliar a sensibilidade ao preço por parte dos compradores, com a finalidade de estimar a plausibilidade de eles alterarem suas compras, acima ou abaixo da variação das vendas em equilíbrio.

4. Identificar os concorrentes e avaliar suas prováveis reações.

5. Identificar compradores para os quais os custos, sensibilidade ao preço e concorrência são significativamente diferentes, e segmentá-los com base no preço, onde for possível.

6. Calcular as consequiências em termos de lucro, aritmética ou graficamente, para diversas e prováveis alterações das vendas.

7. Aceitar ou rejeitar as modificações de preço propostas considerando os benefícios de resultados favoráveis, em comparação com os riscos percebidos de consequiências desfavoráveis. ${ }^{2}$

\section{ANÁLISE BAYESIANA PRÉVIA}

A abordagem da análise bayesiana prévia à modelagem de uma decisão de preço procura lidar com as incertezas inerentes à avaliação de resultados futuros, mediante a incorporação de probabilidades subjetivas. ${ }^{3} \mathrm{O}$ modelo requer que se especifiquem as várias alternativas de decisão, enumerem-se os diversos resultados possíveis, atribuindo-se um valor aos resultados (lucros, perdas ou utilidade), e usando estimativas subjetivas das probabilidades desses resultados a fim de calcular o lucro ou prejuízo esperado (médio) associado a cada alternativa de decisão. Conhecidos esses valores esperados, o tomador de decisão escolhe normalmente a alternativa de maior lucro (ou menor perda) esperado.

Toma-se a decisão sob condições descritas como as de incerteza, uma vez que os rendimentos resultantes podem assumir uma variedade de formas e valores, e as probabilidades destes resultados não são conhecidas com base em algum histórico razoavelmente preciso de sua ocorrência (em cujo caso a decisão poderia ser identificada como tendo sido tomada sob "risco"). Alguns dados históricos são utilizados amiúde para fundamentar estas estimativas das probabilidades dos vários resultados. Em virtude da costumeira escassez de dados e das dificuldades de realizar extrapolações para condições de mercado diferentes em certos aspectos, as probabilidades de cada resultado não são conhecidas com o mesmo nível de exatidão com que se esperaria deparar num jogo de cartas, por exemplo.

Para ilustrar a aplicação da análise bayesiana prévia, imaginemos um modelo simples de decisão de preço. Para fins de discussão e apresentação gráfica (figura 1), o modelo limita o número e variáveis e alternativas, porém na prática encontraríamos poucas dificuldades em ampliar a abordagem para lidar com situações mais complexas,
2. NAGLE, Thomas T. The strategy \& tactics of pricing. New Jersey: PrenticeHall, p. 133

3. 0 nome comumente atribuido a esta abordagem está ligado ao matemático inglês Thomas Bayes (1702-1761), a cujo teorema recorre-se freqüentemente neste tipo de análise de decisăo, embora a análise prévia dispense totalmente 0 uso do teorema. 
especialmente com o emprego de computadores de alta velocidade. $O$ método de análise é certamente apropriado para uma versão ampliada do modelo.

\section{Figura 1:}

Modelo de determinação de preço com emprego da análise bayesiana prévia Onde

$\mathrm{P}_{1}=$ Preço Baixo

$\mathrm{P}_{2}=$ Preço Médio

$\mathrm{P}_{3}=$ Preço Alto

$A_{1}=$ Orçamento de Propaganda Baixo

$\mathrm{A}_{2}=$ Orçamento de Propaganda Médio

$\mathrm{A}_{3}=$ Orçamento de Propaganda Alto

$\mathrm{S}_{1}=$ Vendas Baixas

$\mathrm{S}_{2}=$ Vendas Médias

$\mathrm{S}_{3}=$ Vendas Altas
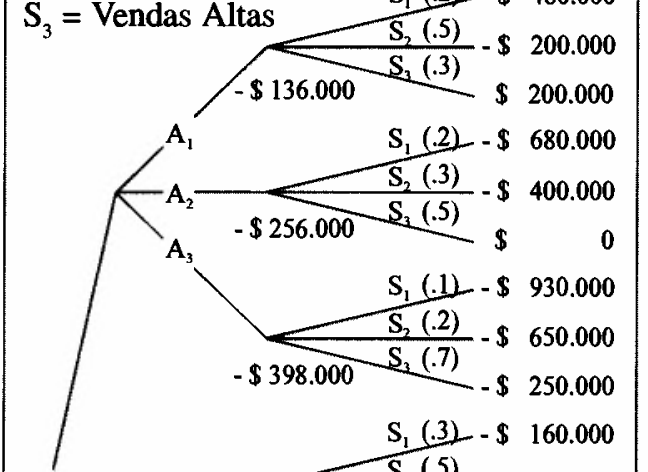

$\mathrm{P}_{1}$

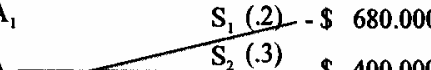

1

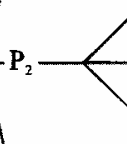

,

$-\$ 256.000 S_{2}(.5)$

$S_{1}(.1)-\$ 930.000$

$\leftarrow \frac{S_{2}(.2)}{S(.7)}-\$ 650.000$

$-\$ 398.000 S_{2}(.7)-\$ 250.000$

$S_{1}(.3)-\$ 160.000$

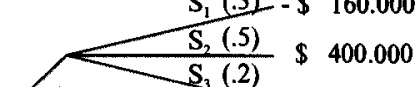

$\$ 392.000 S_{1}(.2) \$ 1.200 .000$

$\mathbf{P}_{3}$

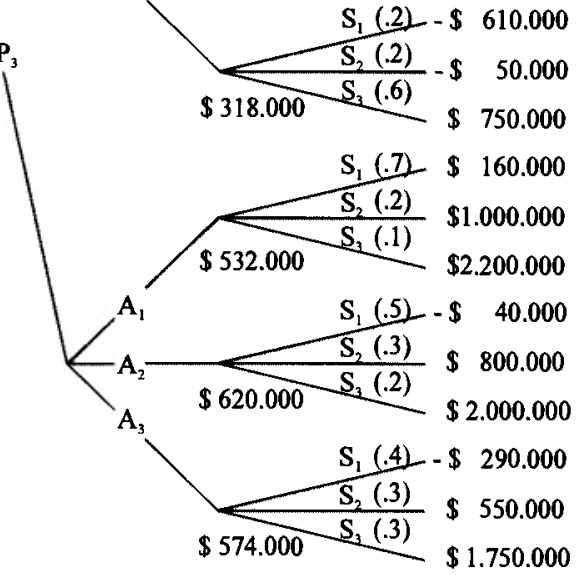

O objetivo principal da descrição deste modelo simples de fixação de preço é discutir a teoria de decisão baseada em informação prévia, representada por uma variável aleatória discreta. Conseqüentemente, formulamos as hipóteses seguintes:

1. Os estados da natureza mencionados no problema a ser analisado ocorrem segundo uma distribuição de variável aleatória discreta.

2. A decisão final será tomada com apoio apenas na informação prévia (isto é, sem o benefício de informação nova ou colhida por amostragem).

3. A utilidade do dinheiro para o tomador de decisão é uma função linear do montante de dinheiro disponível.

Na continuação da resolução deste problema, dispensaremos a restrição de existência apenas de informação prévia e utilizaremos o modelo de análise bayesiana posterior.

Suponha-se que uma determinada companhia planeje lançar um novo brinquedo em Curitiba e tenha decidido limitar o preço de venda a uma de três alternativas : preço unitário baixo $\left(\mathrm{P}_{1}\right)$ de $\$ 8,90$, preço unitário médio $\left(\mathrm{P}_{2}\right)$ de $\$ 12,90$ ou preço unitário alto $\left(\mathrm{P}_{3}\right)$ de $\$ 16,90$. Como apoio promocional, estudam-se três verbas de propaganda, $A_{1}, A_{2}$ e $A_{3}$, baseadas, respectivamente, em dispêndios propostos de $\$ 300.000, \$ 500.000$ e $\$ 750.000$. Como a administração da firma sabe que a escolha de uma verba de propaganda ótima depende em parte do preço de venda a ser cobrado, e vice-versa, formulou-se um modelo que leva em consideração todas as combinações de estratégias de preço e propaganda que estão sendo examinadas.

Dependendo de como o mercado reage ao brinquedo e às suas estratégias de preço e propaganda - de maneira desfavorável, indiferente ou favorável - , podem ocorrer três resultados de vendas possíveis (para simplificar) : 80.000 unidades $\left(S_{1}\right), 150.000$ unidades $\left(S_{2}\right)$ ou 250.000 unidades $\left(S_{3}\right)$ vendidas no período de abrangência dos planos que estão sendo elaborados. Com fundamento nos custos fixos e variáveis da firma projetados para o brinquedo, pode-se estimar o lucro (ou prejuízo) que seria obtido como consequêencia da escolha de uma determinada estratégia e da reação particular do mercado. Por exemplo, a figura 1 mostra que um prejuízo de $\$ 480.000$ poderia ocorrer caso a companhia optasse por uma estratégia de preço baixo e investimento 
em propaganda baixo e se confrontasse com vendas unitárias desfavoráveis.

Com o fito de identificar a melhor estratégia de preço e propaganda para o novo brinquedo, a ser lançado em Curitiba, a administração da companhia deseja selecionar a estratégia que proporcione o maior lucro esperado, de acordo com as várias condições de reação do mercado que poderiam sobrevir. Consequientemente, decide consultar uma equipe de gerentes de vendas experientes a fim de obter estimativas da plausibilidade de cada resposta de vendas para cada combinação de preço e propaganda que está sendo cogitada. ${ }^{4}$ Os números entre parênteses antes das estimativas de lucro (e perda) representam as estimativas subjetivas de probabilidade de cada um destes resultados, desde que uma determinada estratégia de preço e propaganda tenha sido escolhida. Por exemplo, a probabilidade de uma resposta desfavorável de vendas a uma estratégia de preço baixo e investimento em propaganda baixo é 0,2 ; a probabilidade de uma resposta de vendas baixa a uma estratégia de preço alto e gasto em propaganda baixo é 0,7 . Esta variação reflete a crença dos gerentes de vendas consultados de que é necessário um volume maior de propaganda para dar apoio ao preço mais alto. De maneira idêntica, obtiveram-se estimativas para todos os possíveis 27 resultados das nove estratégias alternativas.

O próximo passo consiste em calcular o lucro (ou prejuízo) esperado associado a cada estratégia mediante a multiplicação de cada resultado pela sua probabilidade de ocorrência. Por exemplo, a figura 1 indica que o valor esperado vinculado à estratégia $\mathrm{P}_{1} \mathrm{~A}_{1}$, ou preço baixo e investimento em propaganda baixo, é uma perda de $\$ 136.000:[(0,2 \times(-\$ 480.000)]$ $+[(0,5) \times(-\$ 200.000)]+[(0,3) \times$ (\$200.000)].

Considerando as condições da procura pelo novo brinquedo, a melhor estratégia parece ser a de preço alto e investimento em propaganda moderado, com um lucro esperado de $\$ 620.000$.

Deve-se observar, todavia, que esta estratégia não é desprovida de algum risco, porque há uma probabilidade de 50 por cento de que a companhia perca $\$ 40.000$. Esta perda possível é compensada pelos ganhos substanciais que se presume deverão ocorrer no tempo restante, porém uma empresa mais conservadora poderia preferir adotar a estratégia mais segura baseada em preço alto e gastos em propaganda baixos $\left(\mathrm{P}_{3} \mathrm{~A}_{1}\right)$. Na média, a firma seria mais beneficiada se optasse pela estratégia $P_{3} A_{2}$ (preço alto, investimento médio em propaganda), que maximiza os lucros esperados, tendo em vista que os lucros da empresa seriam maiores no prazo longo. A decisão ótima, portanto, envolve a implementação de uma estratégia baseada em um preço unitário de $\$ 16,90$ e um investimento em propaganda de $\$ 500.000$.

Examinemos sucintamente quatro estratégias alternativas possíveis, sugeridas por Kotler: ${ }^{5}$

1. $P_{1} A_{1}$ ( preço de venda baixo, investimento em propaganda baixo)

A preferência por uma estratégia de penetração lenta no mercado justifica-se pela crença da administração da firma de que o preço baixo estimula uma rápida aceitação do produto e a verba de propaganda baixa contribui para redução de gastos e geração de lucro. Uma estratégia deste tipo é viável nessas condições: (1) o mercado é grande; (2) o mercado demonstra ter uma percepção clara do produto; (3) os consumidores são sensíveis a preço e (4) existe alguma concorrência potencial.

2. $P_{1} A_{3}$ (preço de venda baixo, investimento em propaganda alto)

Este tipo de estratégia é atraente para os executivos de marketing porque costuma estar associada a uma expectativa de penetração de mercado a mais rápida possível e à conquista da maior parcela de mercado possível. Esta estratégia faz sentido nas condições seguintes: (1) o mercado é grande; (2) o mercado desconhece o produto; (3) a maioria dos compradores é sensível a preço; (4) existe uma concorrência potencial forte e (5) os custos unitários de produção da companhia caem com o volume de produção e com a experiência de fabricação acumulada.

3. $\mathrm{P}_{3} \mathrm{~A}_{1}$ (preço de venda alto, investimento em propaganda baixo)

Esta estratégia é conhecida pelo nome de desnatamento de mercado lento. $O$ preço alto contribui para recuperar tanto lucro bruto por unidade quanto possível e a verba de propaganda baixa mantém as despesas mercadológi-
4. Para maiores informações sobre o modelo de inferência bayesiana e seu emprego em previsões de vendas, ver MOTTA Jorge. Decisões na administração mercadologica: uma contribuição da estatística bayesiana, EAESP/FGV, jun. 1994, pp. 296-300.

5. KOTLER, Philip. Marketing management - analysis, planning. implementation and control. New Jersey: Prentice-Hall, 1994, pp. 361-62. 
cas num patamar inferior. As condições de viabilização desta estratégia são as seguintes: (1) o tamanho do mercado é limitado; (2) a maior parte dos consumidores tem conhecimento da existência do produto; (3) os compradores estão dispostos a pagar um preço alto pelo produto e (4) a concorrência potencial não é iminente.

4. $\mathrm{P}_{3} \mathrm{~A}_{3}$ (preço de venda alto, investimento em propaganda alto)

Denominada estratégia de desnatamento rápido, este programa de ação objetiva recuperar tanto lucro bruto unitário quanto possível através do preço alto e convencer o mercado dos méritos do produto, apesar do preço elevado, mediante gastos pesados em promoção. Esta estratégia pode ser viabilizada com fundamento nas premissas seguintes: (1) uma grande proporção do mercado potencial desconhece o produto; (2) aqueles consumidores que tomam conhecimento do produto estão ansiosos por comprá-lo e podem pagar o preço pedido e (3) a empresa enfrenta concorrência potencial e deseja criar preferência de marca.

A decisão ótima em situaçẫo de incerteza, indicada pela análise bayesiana prévia, maximiza os lucros esperados, projetando um resultado positivo de $\$ 620.000$, e propõe a adoção de uma estratégia de preço alto e investimento moderado em propaganda. O preço alto prevê uma recuperação substancial do lucro bruto e o dispêndio em propaganda moderado visa a manter as despesas mercadológicas em nível médio. Presume-se que uma parcela significativa do mercado já conhece o produto (ou o nome da empresa ou produtos similares), que existe uma concorrência potencial e que a com- panhia deseja manter a preferência de marca. Há um risco estimado com probabilidade de $50 \%$ de que a companhia possa sofrer um prejuízo de $\$ 40.000$, compensado, contudo, por uma probabilidade de $50 \%$ de conseguir um lucro entre $\$ 800.000$ e $\$ 2.000 .000$.

Como a estratégia de preço de venda alto e investimento em propaganda baixo ( $\left.\mathrm{P}_{3} \mathrm{~A}_{1}\right)$ pressupõe a satisfação de certos requisitos de viabilização como, por exemplo, a maior parte do mercado tem conhecimento da existência do novo produto e a concorrência potencial não é iminente, os quais não são verdadeíros, na opinião da direção comercial da empresa, decidiu-se desconsiderar essa estratégia e optou-se por comparar as duas estratégias restantes de preço alto com as variantes de investimentos moderado e alto em propaganda. Estas ações contempladas serão avaliadas com o emprego da análise bayesiana posterior.

As alternativas de estratégia disponiveis são as seguintes $\left(\mathrm{E}_{\mathrm{i}}\right)$ :

1. $\mathrm{E}_{1}$ : estratégia de preço alto e investimento em propaganda médio $\left(\mathrm{P}_{3} \mathrm{~A}_{2}\right)$ e

2. $\mathbf{E}_{2}$ : estratégia de preço alto e investimento em propaganda alto $\left(\mathrm{P}_{3} \mathrm{~A}_{3}\right)$.

Os estados da natureza, as respectivas probabilidades e os lucros correspondentes às duas estratégias são indicados no quadro I, conforme os dados observados na figura 1 .

Os dados relativos à estratégia $\mathrm{P}_{3} \mathrm{~A}_{3}$ foram ligeiramente modificados em relação aos valores constantes da figura 1 , com o propósito de permitir uma comparação entre as ações e o desenvolvimento da análise bayesiana posterior. Os valores das probabilidades dos even-

\begin{tabular}{|c|c|c|c|c|c|}
\hline \multicolumn{6}{|l|}{ Quadro I: } \\
\hline \multicolumn{3}{|c|}{$\mathbf{P}_{3} \mathbf{A}_{2}$} & \multicolumn{3}{|c|}{$P_{3} A_{3}$} \\
\hline $\begin{array}{l}\text { Estados da } \\
\text { natureza } \\
\left(S_{\mathrm{j}}\right)\end{array}$ & $\begin{array}{c}\text { Probabilidades } \\
\text { prévias } \\
P\left(S_{j}\right)\end{array}$ & $\begin{array}{l}\text { Lucro } \\
\qquad \$\end{array}$ & $\begin{array}{c}\text { Estados da } \\
\text { natureza } \\
\left(\mathrm{S}_{1}\right)\end{array}$ & $\begin{array}{c}\text { Probabilidades } \\
\text { prévias } \\
\text { P }\left(S_{j}\right)\end{array}$ & $\begin{array}{l}\text { Lucro } \\
\qquad \$\end{array}$ \\
\hline $\begin{array}{c}\mathbf{S}_{1}: \text { vendas } \\
\text { baixas }\end{array}$ & 0,5 & -40.000 & $\begin{array}{c}S_{1}: \text { vendas } \\
\text { baixas }\end{array}$ & 0,5 & -290.000 \\
\hline $\begin{array}{c}\mathrm{S}_{2}: \text { vendas } \\
\text { médias }\end{array}$ & 0,3 & 800.000 & $\begin{array}{c}\mathrm{S}_{2} ; \text { vendas } \\
\text { médias }\end{array}$ & 0,3 & 550.000 \\
\hline $\begin{array}{c}S_{3}: \text { vendas } \\
\text { altas }\end{array}$ & 0,2 & 2.000 .000 & $\begin{array}{c}\mathrm{S}_{3}: \text { vendas } \\
\text { altas }\end{array}$ & 0,3 & 1.750 .000 \\
\hline
\end{tabular}


tos incertos da estratégia $\mathrm{P}_{3} \mathrm{~A}_{3}$ foram alterados a fim de manter compatibilidade com os dados originais da figura 1 .

Os quadros II, III e IV revelam o desempenho das duas estratégias em termos de lucro esperado e possibilitam o cálculo do valor esperado da informação perfeita, ou o custo de decidir em situação de incerteza.

Se a administração da companhia decidir com base no critério da maximização do valor monetário esperado, a opção preferida deverá ser $\mathrm{E}_{1}$, lançar o novo brinquedo com preço alto $(\$ 16,90)$ e investimento em propaganda médio $(\$ 500.000)$. Costuma-se denominar $l u$ - cro esperado sob incerteza o valor esperado do rendimento monetário da melhor estratégia.

Perda de Oportunidade Esperada da Estratégia $P_{3} A_{2}=0(0,5)+0(0,3)+\$ 200.000$ $(0,2)=\$ 40.000$.

Perda de Oportunidade Esperada da Estratégia $\mathrm{P}_{3} \mathrm{~A}_{3}=\$ 160.000(0,5)+\$ 100.000$ $(0,3)+0(0,2)=\$ 110.000$.

Se a administração da empresa optar pelo critério de minimização da perda de oportunidade esperada, a estratégia selecionada deverá ser $E_{\text {, }}$ lançar o novo brinquedo com preço alto $(\$ 16,90)$ e investimento em propaganda médio (\$500.000). Esta estratégia tem o nome de

\begin{tabular}{|c|c|c|c|}
\hline \multicolumn{4}{|c|}{ Quadro II: Estratégia de preço alto e gasto em propaganda médio $\left(\mathbf{P}_{3} \mathbf{A}_{2}\right)$} \\
\hline $\begin{array}{c}\text { Estados da } \\
\text { natureza }\left(S_{j}\right)\end{array}$ & $\begin{array}{c}\text { Probabilidades } \\
\text { prévias } P\left(S_{j}\right)\end{array}$ & $\begin{array}{c}\text { Lucro } \\
(\$)\end{array}$ & $\begin{array}{c}\text { Lucro } \\
\text { ponderado }(\$)\end{array}$ \\
\hline$S_{1}$ : vendas baixas & 0,5 & -40.000 & -20.000 \\
\hline$S_{2}$ : vendas médias & 0,3 & 800.000 & 240.000 \\
\hline$S_{3}$ : vendas altas & 0,2 & 2.000 .000 & 400.000 \\
\hline & 1,0 & & 620.000 \\
\hline
\end{tabular}

Quadro III : Estratégia de preço alto e gasto em propaganda alto $\left(P_{3} A_{3}\right)$

\begin{tabular}{|c|c|c|c|}
\hline $\begin{array}{c}\text { Estados da } \\
\text { natureza }\left(\mathbf{S}_{\downarrow}\right)\end{array}$ & $\begin{array}{c}\text { Probabilidades } \\
\text { prévias } \mathbf{P}\left(\mathrm{S}_{\mathrm{j}}\right)\end{array}$ & $\begin{array}{c}\text { Lucro } \\
(\$)\end{array}$ & $\begin{array}{c}\text { Lucro } \\
\text { ponderado (\$) }\end{array}$ \\
\hline$S_{1}:$ vendas baixas & 0,5 & -200.000 & -100.000 \\
\hline $\mathrm{S}_{2}:$ vendas médias & 0,3 & 700.000 & 210.000 \\
\hline \multirow[t]{2}{*}{$S_{3}:$ vendas altas } & 0,2 & 2.200 .000 & 440.000 \\
\hline & 1,0 & & 550.000 \\
\hline
\end{tabular}

Quadro IV : Tabela de rendimentos e perdas de oportunidade Escolha entre duas estratégias de preço e propaganda

\begin{tabular}{|c|c|c|c|c|}
\hline \multirow[t]{2}{*}{$\begin{array}{c}\text { Estados da } \\
\text { natureza }\left(S_{j}\right)\end{array}$} & \multicolumn{2}{|c|}{$\begin{array}{c}\text { Tabela de rendimentos } \\
\text { estratégias }\end{array}$} & \multicolumn{2}{|c|}{$\begin{array}{c}\text { Tabela de perdas de } \\
\text { oportunidade estratégias }\end{array}$} \\
\hline & $\mathrm{P}_{3} \mathbf{A}_{2}$ & $\mathbf{P}_{3} \mathbf{A}_{3}$ & ${ }_{3} A_{2}$ & $\mathbf{P}_{3} \mathbf{A}_{3}$ \\
\hline$S_{1}:$ vendas baixas & $-\$ \quad 40.000$ & $-\$ 200.000$ & 0 & $-\$ 160.000$ \\
\hline$S_{2}:$ vendas médias & $\$ 800.000$ & $\$ 700.000$ & 0 & $\$ 100.000$ \\
\hline $\mathrm{S}_{3}$ : vendas altas & $\$ 2.000 .000$ & $\$ 2.200 .000$ & $\$ 200.000$ & 0 \\
\hline
\end{tabular}


decisão ótima em situação de incerteza, porque foram examinadas apenas situações em que o tomador de decisão seleciona um entre vários cursos de ação alternativos com base em informação prévia, sem tentar colher informação adicional antes de tomar sua decisão. A decisão

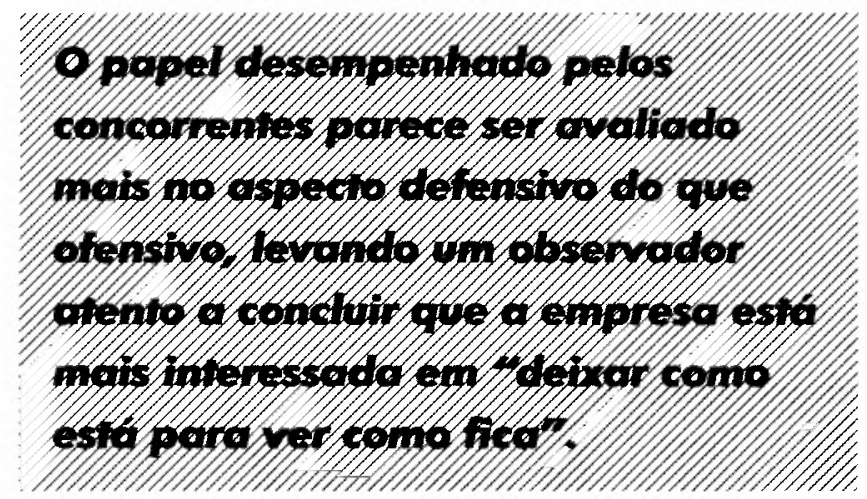

ótima em situação de análise prévia é, portanto, a que maximiza o valor monetário esperado ou minimiza a perda de oportunidade esperada. $O$ custo da incerteza, ou preço que o agente decisório paga pela opção de decidir apoiado apenas em informação prévia, é, no caso da empresa fabricante do novo brinquedo, $\$ 40.000$.

\section{VALOR ESPERADO DA INFORMAÇÃO PERFEITA}

Se o administrador decidisse sempre com apoio de informação perfeita, optaria invariavelmente pela melhor decisão, jamais erraria e, portanto, seu custo de incerteza seria nulo. Para calcular o Valor Esperado da Informação Perfeita (VEIP), recorremos a esta equação:

\footnotetext{
Lucro Esperado com Informação Perfeita

Menos: Lucro Esperado da Decisāo Ótima sob Incerteza

= Valor Esperado da Informação Perfeita (VEIP)

= Perda de Oportunidade Esperada da Decisão Ótima

sob Incerteza

Lucro com Informação Perfeita $=$

$(-\$ 40.000)(0,5)+(\$ 800.000)(0,3)+(\$ 2.200 .000)(0,2)=$ $\$ 660.000$

Lucro Esperado da Decisão Ótima sob Incerteza $=\$ 620.000$ Valor Esperado da Informação Perfeita $=\$ 660.000-\$ 620.000=$ $\$ 40.000$
}

O empresário deveria pagar, no máximo, $\$ 40.000$ por uma informação adicional fornecida por um preditor perfeito, como demonstrado acima.

\section{ANÁLISE BAYESIANA POSTERIOR}

Com o intuito de reduzir o custo esperado da incerteza ( $\$ 40.000$, em nosso exemplo), a direção comercial da companhia decidiu colher informação adicional através da realização de uma investigação de mercado, pois julgou imprudente tomar uma decisão com relação a lançar ou não o novo brinquedo baseada exclusivamente nas probabilidades prévias acerca da reação dos compradores ao novo produto. Suponha-se que várias empresas de estudos de mercado tenham sido consultadas e concluiu-se que a pesquisa poderia chegar a três tipos de resultado amostral sobre o volume provável das vendas, correspondentes aos três estados da natureza:

$\mathrm{x}_{1}$ : a amostra indica vendas baixas

$\mathrm{x}_{2}: \mathrm{a}$ amostra aponta para vendas médias

$\mathrm{x}_{3}: \mathrm{a}$ amostra sinaliza vendas altas

A empresa contratada realiza o estudo de mercado e a amostra investigada conclui em favor de um nível de vendas médio, isto é, $\mathrm{x}_{2}$ foi observado. A confiabilidade do instituto de pesquisa escolhido é a seguinte, com fundamento em estudos semelhantes realizados em anos recentes:

$$
\begin{aligned}
& \mathrm{P}\left(\mathrm{x}_{2} / \mathrm{S}_{1}\right)=0,1 \\
& \mathrm{P}\left(\mathrm{x}_{2} / \mathrm{S}_{2}\right)=0,8 \\
& \mathrm{P}\left(\mathrm{x}_{2} / \mathrm{S}_{3}\right)=0,2
\end{aligned}
$$

Para revisar as probabilidades prévias como consequiência do valor $\mathrm{X}_{2}$ observado na evidência amostral, recorreu-se ao teorema de Bayes, cujo enunciado é o seguinte, para variáveis aleatórias discretas:

$$
\begin{aligned}
& \text { Se } A_{1}, A_{2}, \ldots \ldots ., A j \text { representarem um conjunto de } \\
& \text { J eventos mutuamente excludentes, e se } \\
& B \subset A_{1} U_{A_{2}} \ldots \ldots . . . \mathrm{UA}_{\mathrm{j}} \text { de modo que } \\
& P(B) \leq \sum P\left(A_{j}\right), \text { teremos: } \\
& P\left(A_{j} / B\right)=\frac{P\left(A_{j} B\right)}{P(B)}=\frac{P(B / A j) . P(A j)}{\sum P\left(B / A_{i}\right) P\left(A_{i}\right)}
\end{aligned}
$$

Os quadros V,VI e VII mostram os cálculos das probabilidades posteriores das estratégias $\mathrm{P}_{3} \mathrm{~A}_{2}$ e $\mathrm{P}_{3} \mathrm{~A}_{3}$, após a coleta de evi- 


\begin{tabular}{|c|c|c|c|c|}
\hline $\begin{array}{c}\text { Estados da } \\
\text { natureza } \\
\left(\mathrm{S}_{\mathrm{J}}\right)\end{array}$ & $\begin{array}{c}\text { Probabilidades } \\
\text { prévias } \\
\mathbf{P}\left(\mathrm{S}_{\mathrm{i}}\right)\end{array}$ & \begin{tabular}{|c|} 
Probabilidades \\
condicionais \\
$\mathbf{P}\left(\mathrm{x}_{2} / \mathrm{S}_{\mathrm{i}}\right)$
\end{tabular} & $\begin{array}{c}\text { Probabilidades } \\
\text { conjuntas } \\
\mathbf{P}\left(\mathrm{S}_{\mathrm{j}}\right) \cdot \mathrm{P}\left(\mathrm{x}_{\mathrm{i}} / \mathrm{S}_{\mathrm{i}}\right)\end{array}$ & $\begin{array}{c}\text { Probabilidades } \\
\text { posteriores } \\
\text { P }\left(S_{1} / x_{2}\right)\end{array}$ \\
\hline $\begin{array}{c}\mathrm{S}_{1}: \text { vendas } \\
\text { baixas }\end{array}$ & 0,5 & 0,1 & 0,05 & 0,151 \\
\hline $\begin{array}{l}\mathrm{S}_{2}: \text { vendas } \\
\text { médias }\end{array}$ & 0,3 & 0,8 & 0,24 & 0,728 \\
\hline \multirow[t]{2}{*}{$\begin{array}{c}\mathrm{S}_{3}: \text { vendas } \\
\text { altas }\end{array}$} & 0,2 & 0,2 & 0,04 & 0,121 \\
\hline & 1,0 & 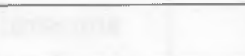 & 0,33 & 1,000 \\
\hline
\end{tabular}

\section{Quadro VI : Cálculo dos lucros esperados posteriores com emprego das probabilidades revisadas estratégia de preço alto/gasto em propaganda médio}

\begin{tabular}{|l|c|c|c|}
\hline \multicolumn{1}{|c|}{$\begin{array}{c}\text { Estados da } \\
\text { natureza }\left(S_{j}\right)\end{array}$} & $\begin{array}{c}\text { Probabilidades } \\
\text { posteriores } \mathbf{P}_{1}\left(\mathrm{~S}_{\mathrm{j}}\right)^{*}\end{array}$ & $\begin{array}{c}\text { Lucro } \\
(\$)\end{array}$ & $\begin{array}{c}\text { Lucro } \\
\text { ponderado }(\$)\end{array}$ \\
\hline $\mathrm{S}_{1}$ : vendas baixas & $\mathbf{0 , 1 5 1}$ & $-\mathbf{4 0 . 0 0 0}$ & $-\mathbf{6 . 0 4 0}$ \\
\hline $\mathrm{S}_{2}$ : vendas médias & 0,728 & $\mathbf{8 0 0 . 0 0 0}$ & $\mathbf{5 8 2 . 4 0 0}$ \\
\hline $\mathrm{S}_{3}$ : vendas altas & $\underline{0,121}$ & $\mathbf{2 . 0 0 0 . 0 0 0}$ & $\mathbf{2 4 2 . 0 0 0}$ \\
\hline & $\mathbf{1 , 0 0 0}$ & & $\mathbf{8 1 8 . 3 6 0}$ \\
\hline
\end{tabular}

Lucro esperado posterior da estratégia $\mathrm{P}_{3} \mathrm{~A}_{2}: \$ 818.360$

* O subscrito 1 indica que a probabilidade prévia foi revisada

Quadro VII : Cálculo dos lucros esperados posteriores com emprego das probabilidades revisadas estratégia de preço alto/gasto em propaganda alto

\begin{tabular}{|l|c|c|c|}
\hline $\begin{array}{c}\text { Estados da } \\
\text { natureza }\left(\mathrm{S}_{\mathrm{j}}\right)\end{array}$ & $\begin{array}{c}\text { Probabilidades } \\
\text { posteriores } \mathrm{P}_{\mathbf{1}}\left(\mathrm{S}_{\mathrm{j}}\right)^{*}\end{array}$ & $\begin{array}{c}\text { Lucro } \\
(\$)\end{array}$ & $\begin{array}{c}\text { Lucro } \\
\text { ponderado }(\$)\end{array}$ \\
\hline $\mathrm{S}_{1}:$ vendas baixas & $\mathbf{0 , 1 5 1}$ & -200.000 & -30.200 \\
\hline $\mathrm{S}_{2}$ : vendas médias & 0,728 & $\mathbf{7 0 0 . 0 0 0}$ & $\mathbf{5 0 9 . 6 0 0}$ \\
\hline $\mathrm{S}_{3}:$ vendas altas & $\underline{0,121}$ & $\mathbf{2 . 2 0 0 . 0 0 0}$ & $\mathbf{2 6 6 . 2 0 0}$ \\
\hline & $\mathbf{1 , 0 0 0}$ & & $\mathbf{7 4 5 . 6 0 0}$ \\
\hline
\end{tabular}

Lucro esperado posterior da estratégia $\mathrm{P}_{3} \mathrm{~A}_{3}: \$ 745.600$

* O subscrito 1 indica que a probabilidade prévia foi revisada.

dência amostral e a observação do resultado $\mathrm{x}_{2}$, e as estimativas dos lucros posteriores das duas estratégias, com base nas probabilidades revisadas.

Como o lucro esperado posterior da estratégia $P_{3} A_{2}$ supera o da estratégia $P_{3} A_{3}$, RAE - v. 37 - n. 2 - Abr./Jun. 1997 a melhor das duas alternativas continua a ser a que favorece a decisão de preço alto completada pela escolha de investimento em propaganda moderado.

Resulta interessante observar que as diferenças entre os lucros esperados das duas 
estratégias variaram de modo pouco significativo, possibilitando, portanto, a confirmação da escolha nas situações de análise prévia e de análise posterior. Os rendimentos das duas ações são sumarizados a seguir:

\begin{tabular}{|l|c|}
\hline \multicolumn{1}{|c|}{$\begin{array}{c}\text { Situação } \\
\text { analisada }\end{array}$} & $\begin{array}{c}\text { Diferença entre os } \\
\text { valores monetários } \\
\text { esperados }\end{array}$ \\
\hline Análise posterior & $\$ 72.760$ \\
Análise prévia & $\$ 70.000$ \\
Variação absoluta & $\$ 2.760$ \\
Variação porcentual & $3,94 \%$ \\
\hline
\end{tabular}

\section{VALOR ESPERADO POSTERIOR DA INFORMAÇÃO PERFEITA}

Pode-se perceber mais claramente o custo da incerteza e o valor da coleta de informação adicional através do cálculo do "valor esperado posterior da informação perfeita", conceituado simplesmente como o rendimento esperado, cujo cálculo fundamenta-se no uso de probabilidades posteriores do processo de tomada de decisão realizada conjuntamente com um preditor perfeito. $\mathrm{Na}$ situação de análise bayesiana com informação prévia, verificou-se que o valor esperado da informação perfeita era $\$ 40.000$. Calculemos, portanto, o valor esperado posterior da informação perfeita.

$\begin{aligned} & \text { Lucro Esperado com Informação Perfeita Posterior }= \\ & =(-40.000)(0,151)+(\$ 800.000)(0,728)+ \\ & (\$ 2.200 .000)(0,121)=\$ 842.560 \\ \text { Menos: } & \text { Lucro Esperado da Decisão Ótima sob Incerteza }= \\ & =\$ 818.360= \\ & =\text { Valor Esperado Posterior da Informação Perfeita }= \\ & =\$ 842.560-\$ 818.360=\$ 24.200= \\ & =\text { Perda de Oportunidade Esperada da Decisão Ótima } \\ & \text { sob Incerteza }=0+0+(\$ 200.000)(0,121)=\$ 24.200\end{aligned}$

6.Para maiores informações sobre a determinação do tamanho ótimo da amostra, consultar MOTTA, Jorge. $0 p$. cit.

7. Nagle, Thomas T. Op. cit., p.30-34. $\$ 24.200$ por uma informação suprida por um preditor perfeito, em contraste com $\$ 40.000$ que ele poderia pagar na situação anterior de disponibilidade de informação prévia subjetiva. O recurso à informação adicional colhida com o estudo de mercado reduziu o custo da incerteza do empresário em $\$ 40.000$ - $\$ 24.200$ $=\$ 15.800$. Embora a informação adicional sobre os estados da natureza obtida através de amostragem não possa ser considerada perfeita, isenta de erros, pode-se concluir que o tomador de decisão deveria pagar um valor inferior a $\$ 24.200$ pela pesquisa de mercado contratada.

O exemplo de coleta de informação amostral descrito acima é, reconhecidamente, algo artificial, uma vez que o tamanho da amostra não foi especificado nem o método de obtenção da informação foi explicitado, porém estas imperfeições poderiam ter sido eliminadas com emprego de técnicas estatísticas apropriadas, cuja dissertação fugiria ao escopo deste artigo. ${ }^{6}$

A figura 2, apresentada a seguir, é um modelo de árvore de decisão relativo à escolha entre duas estratégias alternativas de preço e investimento em propaganda, $E_{1}$ (preço alto e investimento em propaganda moderado) e $E_{2}$ (preço alto e investimento em propaganda alto).

\section{RENDIMENTOS DE EXPERIMENTOS DE PRECIFICAÇÃO}

Alterações de preço podem aumentar ou reduzir os lucros de uma empresa. Para determinar o ponto em que a variação ocorrida nas vendas é suficientemente grande para tornar lucrativa uma redução de preço, ou não lucrativo um aumento de preço, Thomas T. Nagle apresenta um conjunto de seis relações que permitem determinar o montante em cada situação específica. ${ }^{\text {? }}$

Vamos proceder ao desenvolvimento da fórmula do ponto de equilíbrio $\Delta Q$ (no qual o ganho de uma redução de preço é igual à perda ou a perda de um incremento de preço equivale ao ganho) mediante a representação do problema de forma algébrica. São esses os símbolos a ser usados:

$$
\begin{aligned}
& P=\text { preço de venda unitário inicial } \\
& C=\text { custo variável unitário } \\
& Q=\text { quantidade vendida expressa em uni- } \\
& \text { dades }
\end{aligned}
$$

Antes da variação do preço, o lucro obtido foi $(P-C) Q$. 


\section{Figura 2 :}

Diagrama de decisão com emprego da análise posterior estratégia de preço alto $\left(P_{3}\right)$ com investimento médio $\left(A_{2}\right)$ e

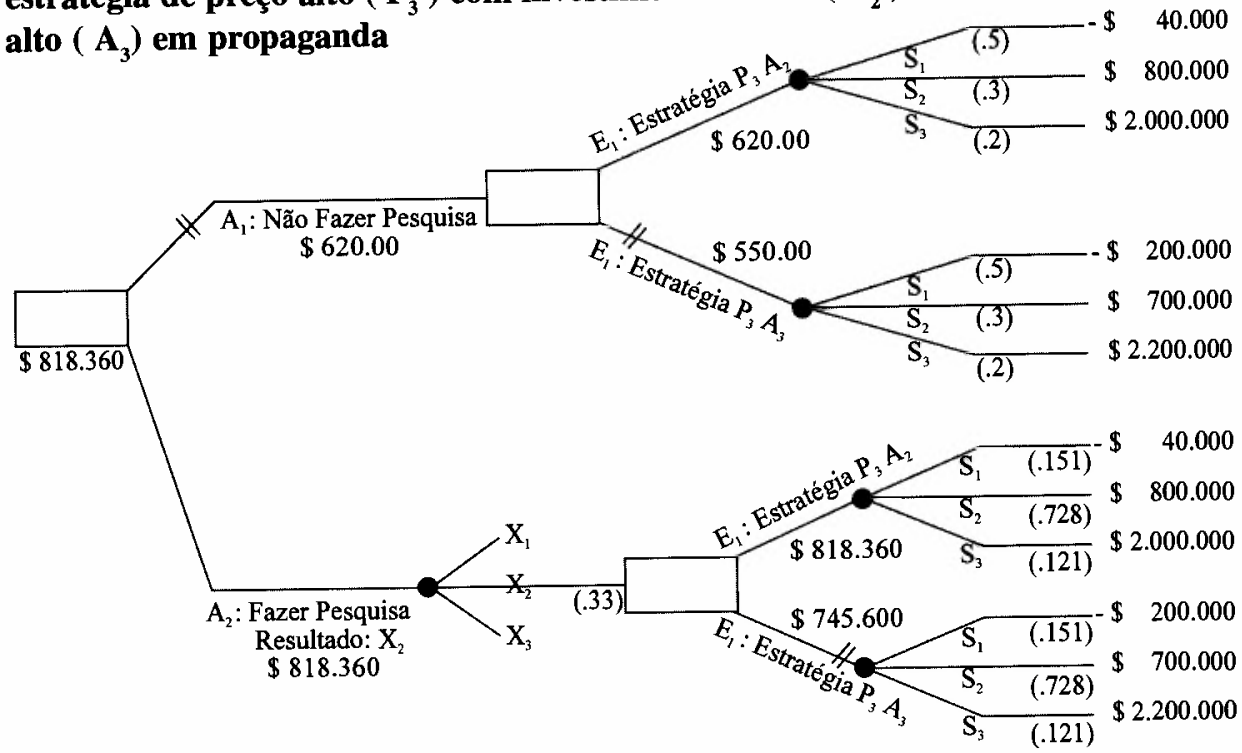

Após a alteração, o lucro passou a ser (P' - C) $Q^{\prime}$, em que $P^{\prime}=P+\Delta P$ e $Q^{\prime}=Q+$ $\Delta Q$. Podemos, portanto, representar o lucro após a variação do preço desta forma : $(\mathrm{P}+$ $\Delta \mathrm{P}-\mathrm{C})(\mathrm{Q}+\Delta \mathrm{Q})$.

Como estamos interessados em descobrir $\Delta Q$ na qual os lucros seriam iguais antes e depois da variação de preço, podemos iniciar o desenvolvimento da fórmula pretendida igualando as duas expressões relativas ao lucro:

$$
(P-C) Q=(P+\Delta P-C)(Q+\Delta Q) \cdot(1)
$$

Observe-se que não estamos considerando na equação (1) o valor relativo aos custos e despesas fixos porque supomos que eles permaneçam constantes e, portanto, não influenciem a decisão de alterar o preço de venda.

Posteriormente, esta hipótese será desconsiderada e serão determinadas as novas relações de ponto de equilíbrio, com introdução da condição de alteração dos custos e despesas fixos em consequiência da variação das vendas causada pela mudança do preço de venda.

Efetuando as operações de multiplicação na equação (1), resulta:

$$
P Q-C Q=P Q+\Delta P Q-C Q+P \Delta Q+\Delta P \Delta Q-C \Delta Q
$$

Podemos simplificar a equação acima sub- traindo PQ e somando CQ a ambos os lados, para obter:

$$
\Delta P Q+P \Delta Q+\Delta P \Delta Q-C \Delta Q=0
$$

Se resolvermos a equação (2) em termos de $\Delta \mathrm{Q}$, teremos a nova equação:

$$
\Delta Q=\frac{-\Delta P Q}{P+\Delta P-C}
$$

Para expressar tudo em porcentagens, basta multiplicar ambos os lados da equação (3) por $1 / \mathrm{Q}$ a seguir multiplicar o lado direito por

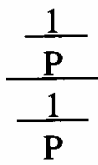

Este passo traz como conseqüência a equação:

\[ \frac{\Delta \mathrm{Q}}{\mathrm{Q}}=\frac{\frac{-\Delta \mathrm{P}}{\mathrm{P}}}{\frac{\mathrm{P}-\mathrm{C}}{\mathrm{P}}+\frac{\Delta \mathrm{P}}{\mathrm{P}}} \]
que também pode ser enunciada assim:
$\begin{aligned} & \text { variaçāo \% das } \\ & \text { vendas em equilíbrio } \\ & \text { em que } \mathrm{IMC}=\text { índice de margem de contribuição. }\end{aligned}$


Podemos representar a fórmula básica da variação das vendas em equilíbrio assim:

1. Variação \% das Vendas em Equilíbrio (sem custos ou despesas fixos incrementais)

$=\frac{(-) \text { Variação Porcentual do Preço }}{\text { Indice de M. de Contribuição }(\%)+\text { Variação \% do Preço }} \times 100$

2. Variação das Vendas Unitárias em Equilíbrio (sem custos ou despesas fixos incrementais)

\begin{tabular}{cc}
\hline $\begin{array}{c}(-) \text { Variação Porcentual do Preço } \\
\text { Indice de M. deContribuição }(\%)+\text { Variação } \% \\
\text { do Preģo }\end{array}$ & $\begin{array}{c}\text { Vendas } \\
\text { Unitárias } \\
\text { Iniciais }\end{array}$ \\
\hline
\end{tabular}

Consideremos, agora, a situação em que a variação do preço de venda acarreta uma alteração das vendas e, ao mesmo tempo, uma variação dos custos e despesas fixos. A equação (1) passa a ser:

$(P-C) Q-C F=(P+\Delta P-C)(Q+\Delta Q)-(C F+\Delta C F)$

Solucionando a equação (5) em termos de $\Delta \mathrm{Q}$, teremos :

$\begin{aligned} \Delta Q \\ Q\end{aligned} \frac{-\frac{\Delta P}{P}}{\frac{P-C}{P}+\frac{\Delta P}{P}}+\frac{\Delta C F}{(P+\Delta P-C) Q}$ (6)

ou

3. Variação $\%$ das vendas em equilíbrio (com custos ou despesas fixos incrementais)

= Fórmula $+\frac{\text { Variação dos custos ou despesas fixos em }}{\text { Nova } \mathrm{MCU} \times 100 \text { vendas unitárias iniciais }}$
(1)
em que MCU = Margem de Contribuição Unitária.

4. Variação das vendas unitárias em equilíbrio (com custos ou despesas fixos incrementais)

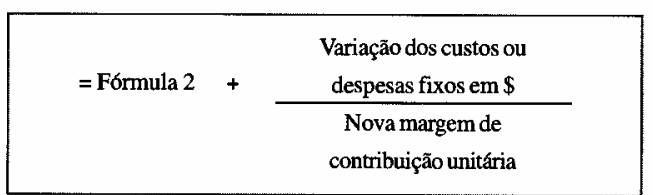

As duas relações seguintes determinam a variação do lucro operacional, resultante de uma alteração do preço de venda.

\section{Variação do lucro operacional}

6. Variação do lucro operacional

$$
\begin{gathered}
\text { =(Variação real das vendas - variação das vendas unitárias em } \\
\text { equilibrio) } \\
\mathrm{x} \\
\text { (nova } \mathrm{MCU} \text { ). }
\end{gathered}
$$

Nos experimentos relacionados com a determinação do preço de venda de um produto ou serviço, surge normalmente o problema de fixar antecipadamente o horizonte de tempo de permanência das conseqüências da decisão tomada pelo empresário. A variação esperada dos lucros por mês, trimestre ou semestre caracteriza adequadamente os resultados alternativos de uma alteração de preço? Na maioria das situações que envolvem decisões de preço, a resposta é não. A maioria dos produtos ou serviços são ofertados no mercado sem contratos com cláusula de obrigatoriedade de manutenção do preço cotado, conferindo à firma vendedora a prerrogativa de ajustar livremente seus preços quando julgar necessário. Os rendimentos dessas alterações de preço experimentais incluem benefícios e custos no prazo longo, além dos seus impactos imediatos sobre os lucros. Nesses casos, o diretor ou gerente responsável pela decisão de preço não deve considerar simplesmente lucros obtidos no prazo curto como o rendimento do resultado alcançado, porém deveria levar em conta os benefícios e custos projetados para o prazo longo. Conseqüentemente, quando as alterações de preço não forem reguladas por contratos restritivos, os resultados lucrativos deveriam receber um peso maior do que os não lucrativos quando se calcular o valor esperado de um experimento de precificação.

Imagine-se o exemplo seguinte, descrito por Nagle em seu texto já citado. ${ }^{8} \mathrm{O}$ gerente de marca de um produto alimentício empacotado, vendido ao atacadista pelo preço de $\$ 16$ por caixa de 10 pacotes, avalia se um aumento ou redução de $\$ 1$ aumentaria os lucros. A companhia fatura 13.700 caixas por semana ao preço atual. Os custos variáveis e evitáveis deste produto montam a $\$ 7$ por caixa. Após examinar a experiência da firma com alterações de preços efetivadas no passado, consultar os especialistas em marketing da empresa, verificar os preços dos produtos concorrentes e analisar cuidadosamente os fatores que influenciam a sensibilidade aos pre- 

registra os resultados potenciais de um aumento de $\$ 1$ e as probabilidades associadas nas colunas 1 e 2 do quadro VIII. Recorrenequilíbrio, o gerente calcula as alterações do lucro semanal relacionadas com os resulta-

Nosso gerente de marca percebe, também,

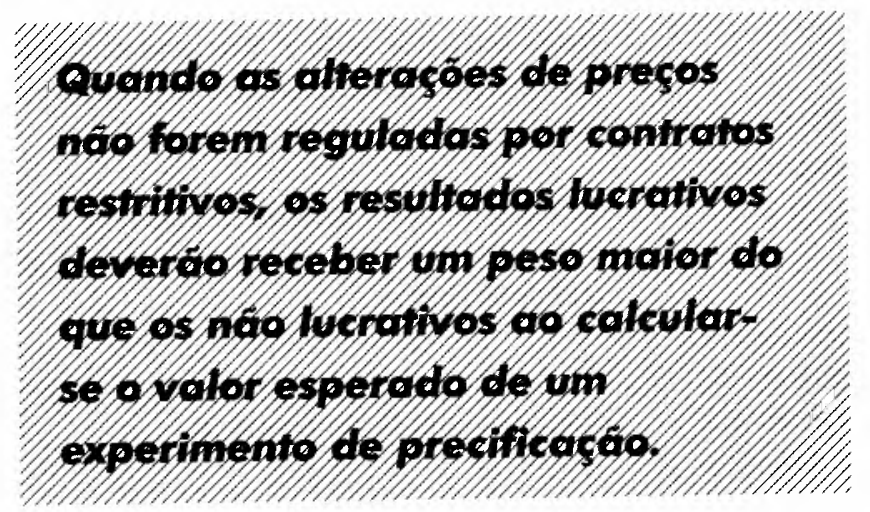

ços dos compradores, o gerente de produto do às fórmulas de variação das vendas em dos inscritos na coluna 3 .

acredita que os lucros adicionais decorrentes de um resultado com um rendimento positivo poderão permanecer, conservadoramente, durante pelo menos um ano (ou 52 semanas). Por conseguinte, sua primeira providência com respeito ao cálculo dos rendimentos totais do experimento consiste em ponderar as variações dos lucros semanais tomando em consideração a condição de serem positivos ou negativos. Os resultados negativos serão multiplicados por 4,3. Desde que 52 semanas representam um intervalo de tempo suficientemente longo para considerar explicitamente o valor do dinheiro ao longo do tempo, nosso gerente decide não multiplicar os resultados positivos por 52 , porém por 48,948 , que é o valor presente de 52 pagamentos semanais de $\$ 1$, descontados a uma taxa de juro igual ao custo de capital dessa companhia, 12 por cento.

Com base na experiência que o rendimento total desse experimento de precificação deve abranger mais do que o simples efeito sobre o lucro semanal. Se o resultado for negativo, o aumento de preço poderá ser revertido em um mês (4,3 semanas) e, assim, minimizar a perda. Por outro lado, se o resultado for positivo, o preço mais alto poderá ser mantido indefinidamente. $\mathrm{O}$ gerente de marca anterior da companhia com variações de pre5 por cento das vendas perdidas em consequiência de um aumento de preço seja perdido permanentemente, ainda que o aumento de preço seja revogado posteriormente. Por esta razão, o gerente aumenta os rendimentos negativos para refletir esse fato. ço, o gerente de produto espera, também, que

Quadro VIII : Valor esperado de um aumento de preço experimental de um produto alimentício empacotado

\begin{tabular}{|c|c|c|c|c|c|}
\hline $\begin{array}{l}\text { (1) } \\
\text { Resultado } \\
\text { alternativo }\end{array}$ & $\begin{array}{l}\text { Probabi- } \\
\text { lidade } \\
(\%) \\
\end{array}$ & $\begin{array}{l}\text { (3) } \\
\text { Variação } \\
\text { dos lucros } \\
\text { semanais } \\
(\$) \\
\end{array}$ & $\begin{array}{l}\text { (4) } \\
\text { Valor } \\
\text { esperado } \\
(\$) \\
\end{array}$ & $\begin{array}{l}\text { (5) } \\
\text { Rendimento } \\
\text { total do } \\
\text { resultado } \\
\left(\$^{*}\right) \\
\end{array}$ & $\begin{array}{l}\text { (6) } \\
\text { Valor } \\
\text { esperado do } \\
\text { resultado } \\
(\$) \\
\end{array}$ \\
\hline $\begin{array}{c}\text { Perda de } 3.000 \\
\text { caixas } \\
\end{array}$ & 05 & -16.300 & -815 & -136.170 & -6.809 \\
\hline \begin{tabular}{|c|}
$\begin{array}{c}\text { Perda de } 2.500 \\
\text { caixas }\end{array}$ \\
\end{tabular} & 10 & -11.300 & -1.130 & - 103.657 & -10.366 \\
\hline $\begin{array}{c}\text { Perda de } 2.000 \\
\text { caixas }\end{array}$ & 25 & -6.300 & - 1.575 & 71.143 & - 17.786 \\
\hline \begin{tabular}{|c|}
$\begin{array}{c}\text { Perda de } 1.500 \\
\text { caixas }\end{array}$ \\
\end{tabular} & 30 & -1.300 & -390 & $-\mathbf{3 8 . 6 3 0}$ & - 11.589 \\
\hline $\begin{array}{c}\text { Perda de } 1.000 \\
\text { caixas }\end{array}$ & 20 & 3.700 & 740 & 181.108 & 36.222 \\
\hline \multirow[t]{2}{*}{\begin{tabular}{|c|}
$\begin{array}{c}\text { Perda de 500 } \\
\text { caixas }\end{array}$ \\
\end{tabular}} & 10 & 8.700 & 870 & 425.848 & $\underline{\mathbf{4 2 . 5 8 5}}$ \\
\hline & & & -2.300 & & \$ 32.257 \\
\hline
\end{tabular}




\begin{tabular}{|c|c|c|}
\hline $\begin{array}{c}\text { Variação } \\
\text { esperada do } \\
\text { lucro semanal } \\
-\$ 2.300\end{array}$ & : & $\begin{array}{l}\text { Valor esperado } \\
\text { do aumento de } \\
\text { preço de } \$ 1 \text { : } \\
\quad \$ 32.257\end{array}$ \\
\hline
\end{tabular}

* Para resultados negativos:

$4.3 \times$ variação dos lucros semanais

- [ 0,05 (variação das vendas) (\$16-\$7) $48,948]$

Para resultados positivos: lucros semanais x 48,948. 48,948 é o valor presente de um fluxo de 52 pagamentos semanais de $\$ 1$, à taxa de juros anual de $12 \%$.

Não obstante o aumento de preço de $\$ 1$ apresentar uma probabilidade de apenas 30 por cento de ser lucrativo e proporcionar um lucro semanal esperado negativo, o valor esperado do aumento de preço alcançou a quantia positiva de $\$ 32.257$. Este resultado se deve à habilidade do gerente de produto de reduzir perdas potenciais decorrentes dos resultados negativos ao reverter o incremento de preço após um mês. Concluiuse, portanto, que a elevada probabilidade de uma perda pequena e controlável ( 70 por cento) merece ser assumida, neste caso, a fim de comprovar a probabilidade menor ( 30 por cento) de que o aumento de preço poderia proporcionar recompensas substanciais num período de tempo mais longo.

A análise bayesiana de decisão aplicada à seleção de alternativas de estratégia de preço de um produto ou serviço requer a execução desses passos: ${ }^{9}$

1. Identificar as opções de estipulação de preço.

2. Para cada opção, determinar os resultados alternativos. Se houver fontes múltiplas de incerteza, os resultados deverão ser identificados através da modelagem das incertezas com o emprego de um gráfico de árvore de decisão.

3. Atribuir probabilidades subjetivas a cada alternativa incerta, indicando-as nos ramos da árvore.
4. Calcular o lucro por intervalo de tempo (por exemplo, semana, mês ou trimestre) associado a cada resultado.

5. Estimar o rendimento total de cada resultado após especificar o horizonte de tempo e o período mínimo durante o qual resultados negativos devem ser permitidos.

6. Calcular o valor esperado de cada resultado, multiplicando o rendimento total pela probabilidade condicional de cada alternativa que o origine.

7. Calcular o valor esperado da opção de preço mediante a soma do valor esperado de cada resultado.

8. Comparar os valores esperados das opções de estipulação de preço.

\section{CONCLUSÃO}

Os métodos de determinação de preços comumente utilizados no Brasil levam em consideração apenas os custos de fabricação e as despesas de comercialização, de financiamento das vendas, de administração das vendas e da empresa analisada em sua totalidade. Não se considera como os custos variam com as alterações das vendas, nem se procura investigar o papel que o preço desempenha nas decisões de compra dos compradores potenciais, nem se pesquisam o comportamento passado e as ações prováveis dos concorrentes. A contribuição da análise bayesiana ao processo de lidar com essa complexidade de fatores incertos que influenciam as decisões de preço, consiste em proporcionar aos administradores um procedimento que lhes permite desdobrar problemas de estipulação de preço em partes separadas, avaliar a incerteza de cada parte através da atribuição de probabilidades subjetivas e reunir essas avaliações separadas a fim de estimar o rendimento final de uma decisão de preço incerta. Com o emprego da análise bayesiana, facilita-se a compreensão de problemas complexos e possibilita-se ao administrador melhorar suas decisões de preço. 